\title{
Hubungan Job Insecurity terhadap Intensi Turnover pada Karyawan Outsourcing
}

\author{
Monica Florida Johan, Rizal Nopriyanto, dan Nurul Ismi Ainun \\ Pascasarjana Magister Profesi Psikologi Universitas Ahmad Dahlan \\ monicafloridajohan@yahoo.co.id
}

\begin{abstract}
This study aims to determine the relationship between job insecurity andintention turnover inemployees outsourcing. The sample in this study wasemployees outsourcing at X Yogyakarta University, totaling 50 people. Data collection was carried out by distributing 2 scales, namely theintention scale turnover(alpha 0.894) and job insecurity (alpha 0.737). The analysis technique used is the product moment withprogram SPSS 19 for windows. The analysis showed that job insecurity onintention turnover was 0.239 with $p=0.047$ (<0.05). It was concluded that job insecurity is related tointention turnover.
\end{abstract}

Keywords:intention turnover, job insecurity

\begin{abstract}
Abstrak
Penelitian ini bertujuan untuk mengetahui hubungan job insecurity terhadap intensi turnover pada karyawan outsourcing. Sampel dalam penelitian ini ialah karyawan outsourcing di Universitas X Yogyakarta yang berjumlah 50 orang. Pengumpulan data dilakukan dengan menyebarkan 2 skala, yaitu skala intensi turnover (alpha 0,894) dan job insecurity (alpha 0,737). Teknik analisis yang digunakan adalah product moment dengan program SPSS 19 for windows. Hasil analisis menunjukkan bahwa job insecurity terhadap intensi turnover sebesar 0,239 dengan $\mathrm{p}=0,047$ $(<0,05)$. Disimpulkan bahwa job insecurity berhubungan dengan intensi turnover.
\end{abstract}

Keywords: intensi turnover, job insecurity

\section{Pendahuluan}

Sumber daya manusia terbagi atas karyawan tetap, karyawan kontrak, dan karyawan outsourcing. Faisal (2009) mengemukakan bahwa karyawan tetap adalah karyawan yang menerima atau memperoleh imbalan dalam jumlah tertentu secara teratur (berkala). Imbalan karyawan tetap dapat berupa gaji, beragam tunjangan, penghasilan tidak teratur seperti bonus, honorarium jasa produksi, gratifikasi dan lain sebagainya, yang didapatkan oleh pegawai swasta, pegawai negeri, maupun pensiunan. Karyawan kontrak dan outsourcing adalah bentuk hubungan kerja yang termasuk dalam kategori precarious work, istilah yang biasanya dipakai secara internasional untuk menunjukkan situasi hubungan kerja yang tidak tetap, waktu tertentu, kerja lepas, tidak terjamin/tidak aman dan tidak pasti (Herawati, 2010). Outsourcing bagi para buruh adalah bentuk praktek perbudakan di era modern dan bentuk perdagangan manusia, terutama outsourcing penyedia jasa pekerja/labor supply (kpsi.or.id, 2015). Pasal 64 UU 13/2003 menjelaskan tentang ketenagakerjaan, mengartikan outsourcing sebagai penyerahan sebagian pelaksanaan pekerjaan kepada perusahaan lain, melalui pemborongan pekerjaan dan penyediaan jasa pekerja/buruh/labor supply. Kedua jenis outsourcing tersebut juga diatur dalam pasal 65 dan pasal 66 UU 13/2003. Listiyarini (6 Januari 2016) melalui portal ekonomi Beritasatu.com menuliskan bahwa saat ini perusahaan atau industri melakukan outsourcing sampai tenaga kerja kontrak, sebab di Indonesia memiliki besaran pesangon yang tertinggi di Asia, dimana terjadi kenaikan upah minimum provinsi (UMP) di semua daerah dalam enam tahun terakhir yakni naik 8-19\%. Informasi tersebut menguatkan pendapat bahwa banyak perusahaan saat ini yang telah melirik untuk menggunakan jasa penyedia jasa kerja/alih daya. Permasalahan-permasalahan tersebut mungkin memicu munculnya intensi turn over pada karyawan outsourcing. Salah satu faktor yang menyebabkan mereka meninggalkan perusahaan adalah pekerjaan tidak sesuai dengan ekpektasi awal dan merasa tidak berkembang. Turnover intention merupakan suatu keadaan dimana 
pekerja memiliki niat atau kecenderungan yang dilakukan secara sadar untuk mencari suatu pekerjaan lain sebagai alternatif di organisasi yang berbeda (Abdillah, 2012). Turnover intention harus disikapi sebagai suatu fenomena dan perilaku manusia yang penting dalam kehidupan suatu perusahaan, baik dari sudut pandang individu maupun sosial, mengingat bahwa tingkat keinginan berpindah karyawan tersebut akan berdampak cukup signifikan bagi perusahaan dan individu yang bersangkutan (Suartana, 2000). Bluedorn (dalam Grant et al, 2001) menyatakan bahwa turnover intention adalah kecenderungan sikap atau tingkat dimana seorang karyawan memiliki kemungkinan meninggalkan organisasi atau mengundurkan diri secara secara sukarela dari pekerjaannya. Harapan yang tidak terpenuhi, ditambah munculnya perasaan kurang berkembang sebagaimana dipaparkan sebelumnya, menjadi salah satu faktor mereka akan meninggalkan pekerjaan. Harninda (dalam Firmanto \& Kistyanto (2013) menyebutnya sebagai turnover intention, yaitu keinginan berpindah karyawan dari satu tempat kerja ke tempat kerja lainnya. Hal demikian berarti bahwa, masih sebatas pada keinginan untuk berpindah, belum sampai pada tahap realisasi yaitu melakukan perpindahan dari satu tempat ke tempat kerja lainnya. Pendapat tersebut sejalan dengan definisi dari Harnoto (2002) bahwa turnover intention adalah kadar atau intensitas dari keinginan untuk keluar dari perusahaan. Turnover ini merupakan tantangan khusus bagi organisasi maupun penyedia jasa tenaga kerja itu sendiri. Sebab, kekosongan karyawan pada posisi tersebut akan sangat berpengaruh terhadap jalannya roda organisasi, yang berarti terhambatnya pencapaian tujuan. Cukup banyak indikasi yang dapat dijadikan acuan untuk menilai intensitas turnover pada karyawan, mulai dari tingkat absensi yang meningkat, mulai malas bekerja, peningkatan terhadap pelanggaran tata tertib kerja, hingga peningkatan protes terhadap atasan. Hasil penelitian yang dilakukan oleh Mawei (2016) menunjukan bahwa Job Insecurity berpengaruh signifikan terhadap Intention to Quit pada karyawan outsourching. Artinya semakin tinggi Job Insecurity maka akan meningkat pula Intention to Quit. Penemuan sebelumnya (Kurniasari, 2004) menyatakan bahwa besarnya intensi turnover (intention to quit) dipengaruhi oleh job insecurity yang berada pada level tidak aman. Hasil penelitian tersebut mengindikasikan adanya pengaruh searah antara job insecurity dan intention to quit. Artinya kenaikan nilai job insecurity akan menaikkan level intention to quit. Semakin tinggi job insecurity, maka akan semakin tinggi intense (niat / keinginan) untuk keluar dari pekerjaan. Penemuan ini konsisten dengan hasil temuan Wardhani (2009) yang juga menyatakan bahwa terdapat hubungan antara job insecurity dengan intention turnover. Model turnover umumnya dimulai dengan premise yang menyatakan bahwa keputusan turnover dikarenakan salah satunya adalah job insecurity (Mawei, 2016). Job insecurity yang dimaksudkan oleh Smithson \& Lewis (2000) dalam Kurniasari (2004) adalah kondisi psikologis karyawan yang menunjukkan rasa bingung atau merasa tidak aman dikarenakan kondisi lingkungan yang berubah-ubah (perceived impermanance). Kondisi ini dapat muncul karena banyaknya jenis pekerjaan yang sifatnya sesaat atau pekerjaan kontrak. Pasewark dan Strawser (1996) dalam penelitiannya menemukan bahwa job insecurity mempengaruhi keinginan berpindah kerja. Hasil penelitian tersebut menunjukkan bahwa job insecurity memiliki hubungan yang signifkan dengan intensi turnover. Job insecurity yang tinggi memiliki hubungan positif terhadap intensi turnover yang juga tinggi. Penelitian yang akan dilakukan memiliki beberapa perbedaan dengan penelitian yang dilakukan oleh Pasewark dan Strawser (1996). Perbedaan pertama terletak pada variabel tergantung yang digunakan. Penilitian yang akan dilakukan menggunakan variabel tergantung intensi turnover, sedangkan variabel tergantung penelitian tersebut menggunakan ketidakamanan kerja. Penelitian yang akan dilakukan menggunakan subjek karyawan outsourcing, sedangkan penelitian tersebut menggunakan subjek akuntansi profesional. Berdasarkan pemaparan di atas, kami tertarik untuk menguji secara langsung dan melakukan analisis untuk mengetahui apkah ada hubungan antara job insecurity terhadap intensi turnover khususnya pada karyawan outsourcing. 


\section{Metodologi}

Berdasarkan tinjauan pustaka yang telah dipaparkan sebelumnya mengenai Hubungan antara Job Insecurity terhadap Intensi Turnover, maka pada penelitian ini variabelvariabel yang digunakan adalah Job Insecurity sebagai variabel eksogenus, sedangkan Intensi Turnover sebagai variabel endogenus. Subjek penelitian adalah karyawan outsourcing di Universitas X Yogyakarta, dimana keseluruhan populasi berjumlah 90 karyawan dengan sampel sebanyak 50 karyawan. Sampel diambil dengan nonprobability sampling, yakni tidak semua elemen dalam populasi memiliki kesempatan yang sama untuk dimasukkan ke dalam sampel penelitian (Kumar, 1996). Jenis nonprobability sampling yang digunakan adalah teknik accidental/incidental sampling, yakni tergantung pada ketersediaan dan keinginan karyawan untuk merespon penelitian (Shaughnessy, Zechmeister \& Zeichmeiser, 2000). Adapun karakteristik yang diinginkan ialah pegawai outsourcing, masa kerja minimal 3 bulan, dan berjenis kelamin laki-laki. Alat ukur penelitian dengan menggunakan skala intensi turnover, dan skala job insecurity. Skala intensi turnover menggunakan skala yang disusun oleh Ardias (2015), yang terdiri dari 15 item mengacu pada aspek yang dipaparkan oleh Mobley, yaitu thinking of quitting, intention to search, dan intention to quit/stay. Hasil uji coba mendapatkan koefisien reliabilitas alpha sebesar 0.948 dengan rentang skor corrected item-total correlation 0,554-0,856. Job insecurity diukur menggunakan Skala Job Insecure Stanford (JIS Scale) yang dimodifikasi oleh Simbolon (2012). Skala terdiri dari 17 aitem mengacu pada aspek severity of threat (keparahan ancaman) dan powerlessness (perasaan tidak berdaya terhadap ancaman). Hasil uji coba yang dilakukan Simbolon (2012) didapatkan koefisien reliabilitas alpha sebesar 0,864 dan rentang indeks daya diskriminasi bergerak antara 0,311-0,654. Pengujian hipotesis menggunakan teknik korelasi product moment. Teknik statistik dalam penelitian ini menggunakan program SPSS 19 for windows.

\section{Hasil dan Diskusi}

Hasil analisis reliabilitas pada kedua skala menggunakan formula Alpha Cronbach diperoleh bahwa kedua skala dapat digunakan sebagai alat pengumpul data yang handal dalam penelitian. Skala intensi turnover (TIS) memiliki koefisien reliabilitas 0,894 (Alpha Cronbach). Skala Job Insecurity (JI) memiliki koefisien reliabilitas 0,737 Alpha Cronbach). Teknik pengolahan data selanjutnya adalah dengan menggunakan korelasi product moment, merupakan alat uji statistik yang digunakan untuk menguji hipotesis asosiatif (uji hubungan) dua variabel bila datanya berskala interval atau rasio. KPM dikembangkan oleh Karl Pearson (Hasan, 1999). Hipotesis dinyatakan diterima jika $\mathrm{p}<0.05$ (signifikan) atau $\mathrm{p}<0.01$ (sangat signifikan) dan tidak diterima jika $\mathrm{p}>$ 0.05. Hasil uji normalitas dikatakan normal apabila Asymp.Sig (taraf signifikansi/p) adalah > 0.05, sedangkan data dikatakan tidak normal apabila Asymp.Sig (taraf signifikansi/p) adalah $<0.05$.

Tabel 1. Uji Normalitas

One-Sample Kolmogorov-Smirnov Test

\begin{tabular}{|ll|r|r|}
\hline & & \multicolumn{1}{|c|}{ TIS } & \multicolumn{1}{c|}{ Jl } \\
\hline Normal Parameters \\
& & 50 & 50 \\
& Mean & 48,9000 & 37,7600 \\
Most Extreme Differences & Absolute & 8,22205 & 7,79995 \\
& Positive &, 051 &, 145 \\
& Negative &, 051 &, 145 \\
Kolmogorow-Smirnov Z & &,- 051 &,- 080 \\
Asymp. Sig. (2-tailed) & &, 364 & 1,026 \\
\end{tabular}

a. Test distribution is Normal. b. Calculated from data. 
Tabel 2. Uji Normalitas Intensi Turnover

\begin{tabular}{|c|c|c|c|}
\hline Uji Asumsi & Indeks & $\mathrm{P}$ & Keterangan \\
\hline Normalitas & $\mathrm{K}-\mathrm{SZ}=0.364$ & 0.999 & Data Normal \\
\hline
\end{tabular}

Pada tabel berikut diketahui K-SZ nya adalah 0,364 dan taraf signitikansi/p nya adalah 0.999 , data dikatakan normal apabila taraf signifikansi/p apabila $>0.05$ dan dikatakan tidak normal apabila taraf signifikansi/p adalah $<0.05$. Jadi, dapat disimpulkan bahwa data tersebut adalah normal serta tidak ada perbedaan sebaran data sample dan populasi, karena taraf signifikansi/ $\mathrm{p}$ data tersebut adalah 0.999 yaitu lebih besar dari 0.05

Tabel 3. Uji Normalitas Job Insecurity

\begin{tabular}{|c|c|c|c|}
\hline Uji Asumsi & Indeks & P & Keterangan \\
\hline Normalitas & K-SZ $=1.026$ & 0.243 & Data Normal \\
\hline
\end{tabular}

Pada tabel berikut diketahui K-SZ nya adalah 1.026 dan taraf signitikansi/p nya adalah 0.243 , data dikatakan normal apabila taraf signifikansi/p apabila $>0.05$ dan dikatakan tidak normal apabila taraf signifikansi/p adalah $<0.05$. Jadi, dapat disimpulkan bahwa data tersebut adalah normal serta tidak ada perbedaan sebaran data sample dan populasi, karena taraf signifikansi/ $\mathrm{p}$ data tersebut adalah 0.243 yaitu lebih besar dari 0.05 .

Tabel 4. Uji Linieritas ANOVA Table

\begin{tabular}{|c|c|c|c|c|c|c|c|}
\hline & & & $\begin{array}{l}\text { Sum of } \\
\text { Squares }\end{array}$ & df & Mean Square & $\mathrm{F}$ & Sig. \\
\hline \multirow[t]{5}{*}{ TIS*JI } & \multirow[t]{3}{*}{ Between Groups } & (Combined) & 1664,905 & 22 & 75,677 & 1,240 & .295 \\
\hline & & Linearity & 189,594 & 1 & 189,594 & 3,107 & ,089 \\
\hline & & Deviation from Linearity & 1475,311 & 21 & 70,253 & 1,151 &, 361 \\
\hline & \multicolumn{2}{|l|}{ Within Groups } & 1647,595 & 27 & 61,022 & & \\
\hline & \multicolumn{2}{|l|}{ Total } & 3312,500 & 49 & & & \\
\hline
\end{tabular}

Pada tabel berikut diketahui $\mathrm{F}$ linierity adalah 3,107 dan taraf signitikansi/p nya adalah 0.089 , serta diketahui F DFL adalah 1,151 dan taraf signitikansi/p nya adalah 0,361 . data dikatakan linier apabila variabel bebas linier dengan variable tergantung jika Sig. F linierity < 0.05 dan Sig. F DFL > 0.05. Jadi, dapat disimpulkan bahwa data tersebut adalah linier, karena taraf signitikansi/p F DFL bya adalah 0.361 yaitu yang lebig besar dari 0.05 .

Tabel 4. Analisis Data

Correlations

\begin{tabular}{|rl|r|r|}
\hline & & \multicolumn{1}{|c|}{ TIS } & \multicolumn{1}{c|}{$\mathrm{Jl}$} \\
\hline TIS & Pearson Correlation & 1 & $.239^{\circ}$ \\
& Sig. (1-tailed) & & .047 \\
& N & 50 & 50 \\
\hline JI & Pearson Correlation & $.239^{\circ}$ & 1 \\
& Sig. (1-tailed) & .047 & \\
N & 50 & 50 \\
\hline
\end{tabular}


Korelasi Pearson atau sering disebut Korelasi Product Moment (KPM) merupakan alat uji statistik yang digunakan untuk menguji hipotesis asosiatif (uji hubungan) dua variabel bila datanya berskala interval atau rasio. KPM dikembangkan oleh Karl Pearson (Hasan, 1999). Hipotesis dinyatakan diterima jika $\mathrm{p}<0.05$ (signifikan) atau $\mathrm{p}<0.01$ (sangat signifikan) dan tidak diterima jika $\mathrm{p}>0.05$. Pada tabel diatas dapat diketahui pearson correlation menunjukkan koefisien korelasi antara dua variable yaitu 0.239 dan p nya adalah 0.047. makan dapat disimpulkan hipotesis tersebut diterima, karena ada hubungan yang signifikan antara JI dengan TIS . Dimana sumbangan variable bebas terhadap variable tergantung adalah $(0.239 \times 0.239) \times 100 \%$ adalah $5,712 \%$.

\section{Hipotesis}

Hipotesis menyatakan bahwa ada hubungan antara job insecurity dengan intensi turnover. Hubungan positif didapatkan dalam hubungan antara job insecurity terhadap intensi turnover sebesar 5,712\%, sehingga menunjukkan semakin tinggi job insecurity maka menyebabkan semakin tingginya intensi turnover, dan sebaliknya. Hal ini berarti bahwa hipotesis diterima.

\section{DISKUSI}

Hasil penelitian yang telah dipaparkan sebelumnya, menunjukkan bahwa job insecurity memiliki hubungan dengan intensi turnover, sebesar 5,712\%. Nilai tersebut menunjukkan bahwa terdapat beberapa faktor lain yang mempengaruhi tingkat intensi turnover, selain job insecurity, diantaranya perceive behavioral control (Ajzen, dalam Azwar, 1997). Berdasarkan penjelasan di atas dapat diartikan bahwa ada hubungan antara job insecurity terhadap intensi turnover pada karyawan outsourcing

\section{Kesimpulan}

Berdasarkan hasil analisis data, didapatkan bahwa ada hubungan antara job insecurity dan intensi turnover. Peneliti selanjutnya, disarankan untuk melakukan penelitian pada sampel yang lebih besar dan juga beragam dari sisi usia, pendidikan, dan gender. Hasil penelitian juga menunjukkan bahwa masih ada variabel-variabel lain yang harus diperhatikan dalam peneltiian ini. Menambah variabel lain yang mempengaruhi intensi turnover akan baik pengaruhnya bagi perkembangan dan peningkatan kualitas organisasi

\section{Referensi}

[1] Abdillah, F. (2012). Hubungan Kohevitas Kelompok Dengan Intensi Turnover Pada Karyawan. Journal of Social and Industrial Psychology. 1(2), 52- 58.

[2] Akbar, F. N. (2013). Pengaruh Motivasi Intrinsik dan Motivasi Ekstrinsik terhadap Kinerja Karyawan pada PT. Perkebunan Nusantara XII Surabaya. Universitas Brawijaya.

[3] Alhempi, R. R. (2015). Pengaruh Komitmen Organisasi dan Ketidakamanan Pekerjaan (Job Insecurity) terhadap Intensi Turnover Tenaga Pengajar di Sekolah ABC Pekanbaru. Jurnal Ekonomi, Manajemen \& Akuntansi I,25(2).

[4] Allen, N.J. dan Meyer, J. P. (1991). The Measurement and Antecedents of Affective, Continuance and Normative Commitment to the Organizational. Journal of Occupational Psychology, 63(1), 118 .

[5] Aninditarini, P.. (2013). Intensi Turnover ditinjau dari Komitmen Organisasi pada Karyawan Rumah Sakit Qolbu Insan Mulia (QIM) Batang. Naskah Publikasi. Fakultas Psikologi Universitas Muhammadiyah Surakarta.

[6] Anwar, R., Zaika, Y., \& Wahyuni, A. S. (2014). Analisa faktor-faktor yang mempengaruhi turnover intention (keinginan berpindah) karyawan pada perusahaan jasa konstruksi. Jurnal rekayasa sipil, $8(2)$.

[7] Arnold, H. J. \& Fieldman, D. C. (1982). A Multivariate Analysis of the Determinan of Job Turnover. Journal of Applied Psychology, 67, 3560-360. 
Monica Florida Johan, Rizal Nopriyanto, dan Nurul Ismi Ainun

Psyche 165 Journal Vol 13 No 1 (2020 ) 60 - 66

[8] Ardias, W. S. (2015). Peran Perceived Organizational Support sebagai Moderator pada Hubungan antara Job Stress dengan Intensi Turnover (Tesis). Program Magister Psikologi Profesi Fakultas Psikologi UGM, Yogyakarta.

[9] Ashford, S. J., Lee, C.,\& Bobko, P. (1989). Content, causes, and consequences of job insecurity: A theory-based measure and substantive test. Academy of Management Journal, 32(4), 803-829.

[10] Aulia. (2015). Komitmen Organisasi Ditinjau dari Kecerdasan Emosi dan Keterikatakan Kerja. Fundamental. Yogyakarta: Universitas Ahmad Dahlan.

[11] Azwar, S. (1997). Sikap manusia: Teori dan pengukurannya (Edisi kedua). Yogyakarta: Pustaka Pelajar.

[12] Bateman, C. (2014). Does Psychological Capital Moderate The Degree of Stress and Turnover Intention Associated With Experienced Workplace Incivility: An Exploration in The South African Context. A dissertation submitted in partial fulfilment of the requirements for the award of the degree of Master of Social Science in Organizational Psychology. University of Cape Town.

[13] Bothma, C.F.C., \& Roodt, G. (2013). The validation of the turnover intention scale. SA Journal of Human Resource Management/SA Tydskrif vir Menslikehulpbronbestuur, 1(1).

[14] Chaplin, J. P. (2006). Kamus Lengkap Psikologi. Jakarta : PT Grafindo Persada.

[15] Faisal, G. (2009). How to be Smarter Tax Payer. Jakarta : Grasindo.

[16] Firmanto, T. dan Kistyanto, A. (2013). Pengaruh Budaya Kerja Kekeluargaan terhadap Turnover Intention Karyawan melalui Komitmen Afektif. Jurnal Ilmu Manajemen, 1(1).

[17] Grant, K., Cravens, D. W., Low, G. S. and Moncrief, W.C. (2001). "The Role of Satisfaction with Territory Design on the Motivation, Attitudes, and Work Outcomes of Sales People", Journal of the Academy of Marketing Science, 29,(2).

[18] Harnoto. (2002). Manajemen Sumber Daya Manusia. Jakarta: Prehallindo.

[19] Hartley, J., Jacobson, D., Klandermans, B., \& Van Vurren, T. (1991). Job Insecurity: Coping with Jobs at Risk. London: Sage.

[20] Hasan, I. (1999). Pokok-Pokok Materi STATISTIKA 2 (Statistik Inferensif). Jakarta: Bumi Aksara.

[21] Hellgren, J., Sverke \& Isaksson, K. (1999). A Two-Dimensional Approach to Job Insecurity: Consequences for Employee Attitudes and Well-Being. Europian Journal of Work and Organizational Psychology, 8(2).

[22] Herawati, R. (2010). Kontrak dan Outsourcing Harus Makin Diwaspadai. Bandung: Akatiga.

[23] Hom, P. W., and Griffeth, R. W. (1995). Employee Turnover. Cincinnati, OH: South-Western.

[24] Ito, J., \& Brotheridge, C. (2007). Exploring the Predictor and Consequences of Job Insecurity's Components. Journal of Managerial Psychology, 22, 40-64.

[25] Ivancevich, J. M. et al. (2007). Perilaku \& Manajemen Organisasi. Erlangga: Jakarta.

[26] Kinnunen, U., Mauno, S., Natti, J., \& Happonen, M. (2000). Organizational antecedens and outcomes of job insecurity: A Longitudinal study in three organizational in Finland. Journal of Organizational Behavior, 21(1,) 443-459.

[27] Kreitner., \& Kinicki. (2010). Organizational behavior ninth edition. Boston: McGraw-Hill.

[28] Kumar, V., Abbas, AK., \& Fausto, N. (2005). Pathologic Basic of Disease 7th. ed. Philadelphia Elsavier Saunders.

[29] Kurniasari, L. (2004). Pengaruh Komitmen Organisasi dan Job Insecurity Karyawan terhadap Intensi Turnover (Tesis tidak diterbitkan). Program Pascarsarjana Pengembangan SDM Universitas Airlangga, Surabaya.

[30] Listiyarini, T. (2016). Ini Penyebab Angka Kemiskinan RI Meningkat. Portal Ekonomi Beritasatu.com.

[31] Luthans, F. (2011). Organizational behavior. New York: The McGraw-Hill Companies, Inc.

[32] Maier, N. R. F. (1971). Psychology in Industry. Cambridge: The Riverside Press.

[33] Mawei, R. (2016). Job Insecurity, Komitmen Organisasi Karyawan Dan Kepuasan Kerja Serta Dampaknya Terhadap Intention To Quit. Jurnal Riset Bisnis dan Manajemen, 4(1),17-32.

[34] Mobley, W. H. (1986). Pergantian Karyawan: Sebab, Akibat dan Pengendaliannya (Terjemahan). Jakarta: Pustaka Binaman Pressindo.

[35] Mobley, W. H. (2000). Pergantian Karyawan: Sebab, Akibat dan Pengendaliannya. Terjemahan. Jakarta: Pustaka Binaman Pressindo.

[36] Mowday, R. T., Porter, L. W., and Steers, R. M. (1982). Employee Organizational Lingkage: The Psychology of Commitment, Abseintism, and Turnover. London: Academic Press. 
[37] Naswall, K., \& De Witte, H. (2003). Who feels insecure in europe predicting job insecurity from background variabels. Journal Economic and Industrial Democracy, 24(2), 189-215.

[38] Nursalam. (2008). Konsep dan Penerapan Metodologi Penelitian Ilmu Keperawatan (Pedoman skripsi, Tesis, dan Instrumen Penelitian Keperawatan Edisi 2. Jakarta: Salemba Medika.

[39] Pasewark, W. R. \& Strawser, J. R. (1996). The Determinants and Outcomes Associated with Job Insecurity in A Professional Acounting Environment. Behavioral Research in Accounting, 8.

[40] Prabowo, S., \& Yunanti, Y. D. (2014). Komitmen organisasi ditinjau dari job insecurirty pada karyawan outsourcing. Jurnal Psikodimensia, 13(1).

[41] Ridlo, I. A. (2012). Turnover Karyawan "Kajian Literatur". Surabaya: Public Health Movement.

[42] Robbins, S.P., \& Judge, T. A. (2008). Perilaku organisasi. Jakarta: Salemba Empat.

[43] Setiawan, A. \& Hadiyanto. (2008). Job Insecurity dalam Organisasi (Skripsi tidak diterbitkan). Fakultas Ekonomi Jurusan Manajemen Universitas Kristen Maranatha, Bandung.

[44] Shaughnessy, J.J., Zechmeister, E.B \& Zechmeister, J.S. (2012). Research Methods in Psychology 9th Edition. Singapore: Mc Graw Hill.

[45] Simbolon, A. K. O. (2012). Peranan Moderator Locus of Control dalam Pengaruh Job Insecurity Terhadap Turnover Intention (Tesis Tidak Diterbitkan). Universitas Gajah Mada, Yogyakarta.

[46] Steers, R.M. (1988). Introduction to Organizational Behavior ( $3^{\text {rd }}$ ed). Scott, Foresman Company.

[47] Steers, R. M., \& Porter, R. W. (1983). Motivation and Work Behavior. New York: Mc Graw Hill.

[48] Suartana, I Wayan. (2000). Anteseden dan Konsekuensi Job Insecurity dan Keinginan Berpindah pada Internal Auditor. Tesis. Magister Sains Universitas Gadjah Mada, Yogyakarta.

[49] Triaryati, N. (2003). Pengaruh Adaptasi Kebijakan Mengenai Work Family Issue terhadap Absen dan Turnover. Jurnal Manajemen Kewirausahaan, 5(1).

[50] Wahyuni, A. S., Zaika, Y., \& Anwar, R. (2014). Analisis Faktor-faktor yang Mempengaruhi turnover intention (keinginan berpindah) karyawan pada perusahaan jasa instruksi. Jurnal Rekayasa Sipil, 8(2).

[51] Wanous, J. P. (1980). Organizational Entry, Recruitment, Selection, and Socialization of Newcomers. Philippines: Addison Wesley Publ.co.

[52] Wardhani, S.N. (2009). Hubungan Stres Kerja, Ketidakamanan Kerja (Job Insecurity) dengan Keinginan Berpindah (Turnover Intention) Karyawan CMO PT. Adira Dinamika Multifinance Pamekasan Madura.Abstrak. $\quad$ karya- ilmiah.um.ac.id/index.php/BKPsikologi/article/view/3310/1138.

[53] Yanita, P., \& Masdupi, E. (2014). Pengaruh kompensasi, komitmen organisasi, dan job insecurity terhadap intention to turnover pada dosen Sekolah Tinggi Ilmu Ekonomi Sakti Alam Kerinci. Jurnal riset manajemen bisnis dan publik.

[54] Undang-undang No.13 Tahun 2003. Tentang Ketenagakerjaan. Bab XI Pasal 56, 57, 58 dan 59

[55] https://kpsi.or.id. 